\title{
A NEW JOURNAL BASED ON AN OLD IDEA...THIRTY YEARS LATER
}

On a hot, muggy afternoon in late August 1987, two young Mesoamericanist archaeologists-one a Mayanist, the other a Mexicanist - sat in a borrowed office at Vanderbilt University and began a conversation about the need for a new journal of Mesoamerican studies. Steve Houston and I had just arrived on campus to become part of the expansion of the newly formed Department of Anthropology. Renovation of our offices was incomplete, so we shared an office in the Department of Sociology for a few weeks. Our conversations about the need for a new journal continued as the days and weeks passed, and eventually we decided that we would take on the challenge of founding a new journal. Thus was born the idea for Ancient Mesoamerica (AM).

We spent part of the fall semester 1987 composing a prospectus, in which we argued that Mesoamerica was experiencing an explosion of academic research and new field projects and that publication had not kept pace with the research, in part because of a lack of suitable journal outlets. American Antiquity, because of its broad geographic scope, could not handle more than a fraction of all the material coming out of the new projects in Mesoamerica, and other journals at the time were either too narrow in scope, financially limited, or published only intermittently.

We proposed a new alternative, and here I paraphrase from our 1987 prospectus. AM would be a peer-reviewed academic journal, publishing semiannually and including original research papers, reports of field research, and theoretical articles. We proposed that the new journal could provide an international forum for the methods, theory, substance, and interpretation of Mesoamerican archaeology. We envisioned our main emphasis to be on pre-Columbian archaeology, but we also proposed to include papers on historical archaeology, ethnohistory, historical linguistics, epigraphy, ethnography, ethnoarchaeology, bioarchaeology, and art history. By accommodating these fields of research, we also opened the chronological scope to include the colonial and modern periods. With regard to content, we enumerated a detailed list of possible topics such as the origins of agriculture, the political economy of city-states and empires, the development and functions of early writing systems, advances in survey and excavation methods and technologies, chronological revisions of culture-historical sequences, reconstructions of household and community organization, the ecological impact of pre-Columbian land use, and effective ways to deal with looting and unprovenanced cultural materials. We also began to assemble names of and commitments from senior Mesoamericanist colleagues who would support the proposal and serve on the editorial board.
In late January 1988, we sent our proposal to a number of university presses. I think we sent it to seven or eight publishers, at least. The responses were all generally negative, with the notable exception of Cambridge University Press (CUP), the oldest press in the world. On February 4, 1988, we received a letter from the Journals Director putting us in contact with James (Jim) Alexander, Journals Manager in the CUP New York office. Jim was a gentleman, a dedicated publishing professional, and a visionary. He liked our proposal. We talked to him by telephone, and we exchanged a few more letters. On March 1, 1988 (31 years ago to the day on which I write these lines), he wrote, "The initial reaction at the Press is that the idea is editorially intriguing and certainly warrants further study." Jim guided us through a revision of the proposal that was sent out for independent review as well as internal CUP evaluation. The reviews took place during the summer and, in a letter dated August 17, 1988, Jim quoted one of his colleagues in Cambridge, "I'm sorry that I didn't think of the idea myself!" And he followed with his personal opinion, that with such "a good idea, it is easy to see how you have gotten such favorable comments from some of the best names in American anthropology."

The outcome now was assured. By October 11, we had a new version of the prospectus and a draft memorandum agreement. By this time, everyone knew that the Society for American Archaeology (SAA) was in the process of launching Latin American Antiquity (LAQ), and it remained to resolve any possible competition or conflict. Steve and I felt that the market was big enough for two new journals, and that AM would appeal to a different and broader readership than LAQ. We were right, and the two new publishing endeavors, AM and LAQ have prospered in a complementary, rather than a competitive, relationship.

In 1989, we continued with the task of assembling the Editorial Board and worked on content for the first issue. The Press approved the final contract on March 1, 1989 (exactly 30 years ago). The first call for papers went out at about the same time. The Press Syndicate approved the Editorial Board (all 31 members) on April 28. The premiere issue, Vol. 1, No. 1, appeared a year later in spring 1990.

Since then until the present time, including Vol. 29, No. 2 (fall 2018), AM has published 646 articles representing the work of 1,188 authors (I am grateful to Marlon Escamilla for compiling these statistics). Two distinguished members of the Editorial Board, Payson Sheets and Michael Smith, share the honor of most-published author in the pages of AM (seven articles each). Eight members of the first Editorial Board provide continuity by remaining on the Board today: Frances Berdan, Ronald Bishop, Arthur Demarest, Norman 


\section{Announcing an Important New Journal...}

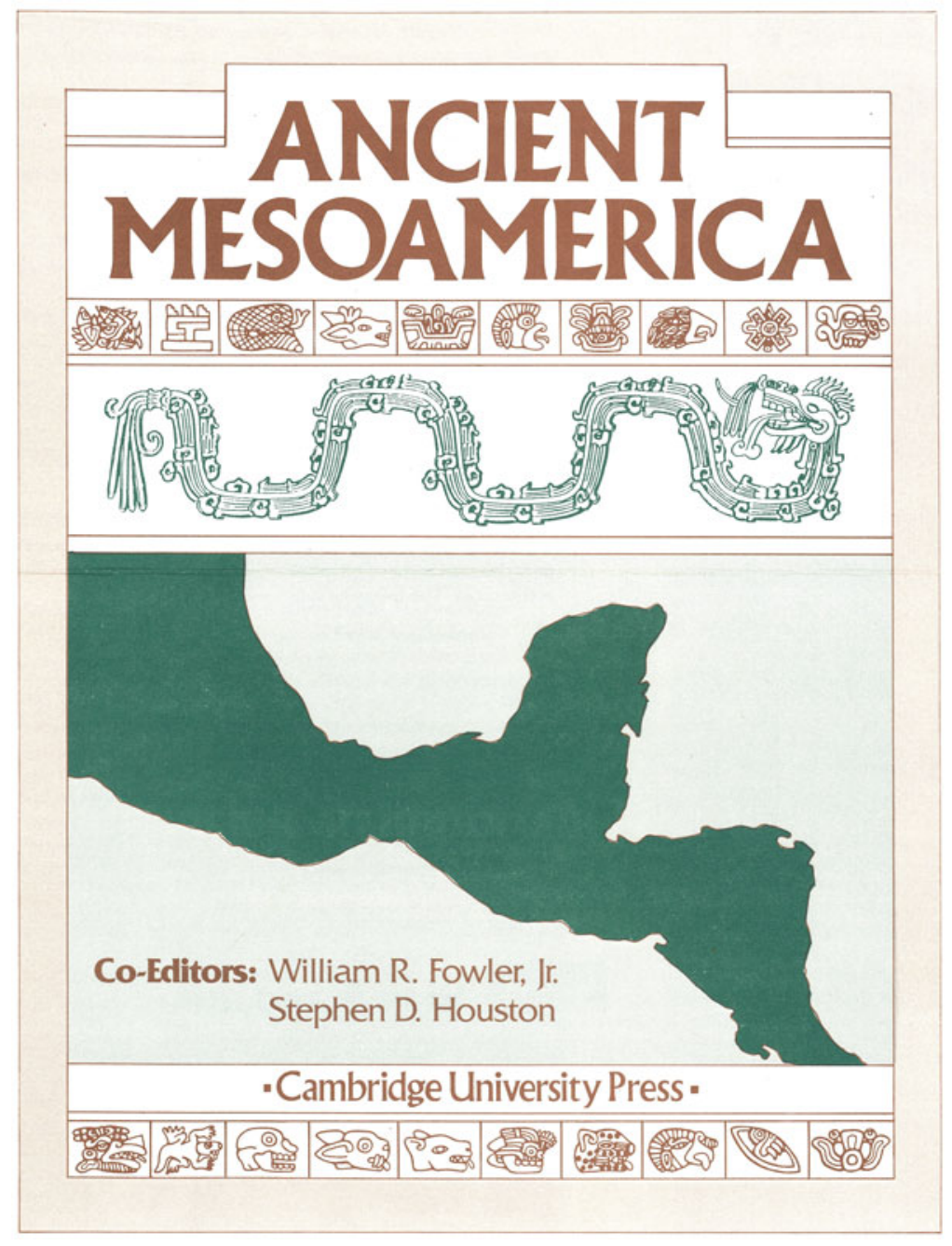

Figure 1. Cover page of first flyer for Ancient Mesoamerica, Vol. 1, No. 1, late 1989.

Hammond, Kenneth Hirth, Jeffrey Parsons, Payson Sheets, and Michael Smith. Steve Houston also serves on the Board, also providing continuity with the founding years. Many other members of the Board have served more than 20 years. Sadly, too many Editorial Board members are no longer of this world, and Jim Alexander passed away all too soon in 1995. But we remain in capable hands at CUP. James McIntyre, Senior Commissioning Editor of Humanities and Social Science Journals at CUP in Cambridge, for the past few years has given AM much devoted attention, care, and support.
During these 30 years, we have seen many changes, but we have remained true to our mission, as stated in the first issue (Fowler and Houston 1990). Changes in the technology of communications and publishing have made the job easier and more expeditious. Changes in the technologies of archaeology and related fields of study have produced results that we could not have imagined 30 years ago, but the results fit very comfortably within the AM framework as we began to imagine it on that hot afternoon in late August 1987.

William R. Fowler

\section{ACKNOWLEDGMENTS}

I thank Nan Gonlin for the encouragement and ideas that she gave me as I was preparing to write these remarks. I am very grateful to all our readers, authors, reviewers, board members, and editors for making AM the great journal that it is.

\section{REFERENCE}

Fowler, William R., and Stephen D. Houston

1990 Editorial Remarks: A New Journal Based on an Old Idea. Ancient Mesoamerica 1:1-2. 